\title{
2012 Update of the 2008 American College of Rheumatology Recommendations for the Use of Disease-Modifying Antirheumatic Drugs and Biologic Agents in the Treatment of Rheumatoid Arthritis
}

\author{
JASVINDER A. SINGH, ${ }^{1}$ DANIEL E. FURST, ${ }^{2}$ ASEEM BHARAT, ${ }^{1}$ JEFFREY R. CURTIS, ${ }^{1}$ \\ ARTHUR F. KAVANAUGH, ${ }^{3}$ JOEL M. KREMER, ${ }^{4}$ LARRY W. MORELAND, ${ }^{5}$ JAMES O'DELL, ${ }^{6}$ \\ KEVIN L. WINTHROP, ${ }^{7}$ TIMOTHY BEUKELMAN, ${ }^{1}$ S. LOUIS BRIDGES JR., ${ }^{1}$ W. WINN CHATHAM, ${ }^{1}$ \\ HAROLD E. PAULUS, ${ }^{2}$ MARIA SUAREZ-ALMAZOR ${ }^{8}$ CLAIRE BOMBARDIER, ${ }^{9}$ MAXIME DOUGADOS, ${ }^{10}$ \\ DINESH KHANNA, ${ }^{11}$ CHARLES M. KING, ${ }^{12}$ AMYE L. LEONG, ${ }^{13}$ ERIC L. MATTESON, ${ }^{14}$ \\ JOHN T. SCHOUSBOE, ${ }^{15}$ EILEEN MOYNIHAN,${ }^{16}$ KAREN S. KOLBA, ${ }^{17}$ ARCHANA JAIN, ${ }^{1}$ \\ ELIZABETH R. VOLKMANN,${ }^{2}$ HARSH AGRAWAL, ${ }^{2}$ SANGMEE BAE, ${ }^{2}$ AMY S. MUDANO, ${ }^{1}$ \\ NIVEDITA M. PATKAR, ${ }^{1}$ AND KENNETH G. SAAG ${ }^{1}$
}

Guidelines and recommendations developed and/or endorsed by the American College of Rheumatology (ACR) are intended to provide guidance for particular patterns of practice and not to dictate the care of a particular patient. The ACR considers adherence to these guidelines and recommendations to be voluntary, with the ultimate determination regarding their application to be made by the physician in light of each patient's individual circumstances. Guidelines and recommendations are intended to promote beneficial or desirable outcomes but cannot guarantee any specific outcome. Guidelines and recommendations developed or endorsed by the ACR are subject to periodic revision as warranted by the evolution of medical knowledge, technology, and practice.

The American College of Rheumatology is an independent, professional, medical and scientific society which does not guarantee, warrant, or endorse any commercial product or service.

\section{Introduction}

The American College of Rheumatology (ACR) most recently published recommendations for the use of diseasemodifying antirheumatic drugs (DMARDs) and biologic

The views expressed in this article are those of the authors and do not necessarily reflect the position or policy of the Department of Veterans Affairs or the United States government.

Supported by a research grant from the American College of Rheumatology.

${ }^{1}$ Jasvinder A. Singh, MBBS, MPH, Aseem Bharat, MBBS, MPH, Jeffrey R. Curtis, MD, MPH, Timothy Beukelman, MD, MSCE, S. Louis Bridges Jr., MD, PhD, W. Winn Chatham, MD, Archana Jain, MD, Amy S. Mudano, MPH, Nivedita M. Patkar, MD, MSPH, Kenneth G. Saag, MD, MSc: University of Alabama at Birmingham; ${ }^{2}$ Daniel E. Furst, MD, Harold E. Paulus, MD, Elizabeth R. Volkmann, MD, Harsh Agrawal, MD, Sangmee Bae, BS: University of California, Los Angeles; ${ }^{3}$ Arthur F. Kavanaugh, MD: University of California, San Diego; ${ }^{4}$ Joel M. Kremer, MD: Albany Medical College, Albany, New York; ${ }^{5}$ Larry W. Moreland, MD: University of Pittsburgh, agents in the treatment of rheumatoid arthritis (RA) in 2008 (1). These recommendations covered indications for use, monitoring of side effects, assessment of the clinical response to DMARDs and biologic agents, screening for tuberculosis (TB), and assessment of the roles of cost and

Pittsburgh, Pennsylvania; ${ }^{6}$ James O'Dell, MD: University of Nebraska, Omaha; ${ }^{7}$ Kevin L. Winthrop, MD, MPH: Oregon Health and Science University, Portland; ${ }^{8}$ Maria SuarezAlmazor, MD, MPH: University of Texas MD Anderson Cancer Center, Houston; ${ }^{9}$ Claire Bombardier, MD, MSc: Toronto General Research Institute, Toronto, Ontario, Canada; ${ }^{10}$ Maxime Dougados, MD: Hôpital Cochin, Paris, France; ${ }^{11}$ Dinesh Khanna, MD, MSc: University of Michigan, Ann Arbor; ${ }^{12}$ Charles M. King, MD: North Mississippi Medical Center, Tupelo; ${ }^{13}$ Amye L. Leong, MBA: Healthy Motivation, Santa Barbara, California; ${ }^{14}$ Eric L. Matteson, MD, MPH: Mayo Clinic, Rochester, Minnesota; ${ }^{15}$ John T. Schousboe, MD, PhD: University of Minnesota and Park Nicollet Clinic, Minneapolis; ${ }^{16}$ Eileen Moynihan, MD: Highmark Medicare Services, Woodbury, New Jersey; ${ }^{17}$ Karen S. Kolba, MD: Pacific Arthritis Center, Santa Maria, California. 


\section{Significance \& Innovations}

- These 2012 recommendations update the 2008 American College of Rheumatology recommendations for the treatment of rheumatoid arthritis (RA).

- The recommendations cover the use of diseasemodifying antirheumatic drugs and biologic agents in patients with RA, including switching between drugs.

- We address screening for tuberculosis reactivation, immunization, and treatment of RA patients with hepatitis, congestive heart failure, and/or malignancy in these recommendations, given their importance in RA patients receiving or starting biologic agents.

patient preference in decision making for biologic agents (1). Recognizing the rapidly evolving knowledge in RA management and the accumulation of new evidence regarding the safety and efficacy of existing and newer ther-

Dr. Singh has received consultant fees, speaking fees, and/or honoraria (less than $\$ \mathbf{\$ 1 0 , 0 0 0}$ each) from Allergan, Ardea, Savient, and Novartis, and (more than \$10,000) from Takeda, has received an investigator-initiated grant from Savient and Takeda, and is an executive member of an international organization, Outcome Measures in Rheumatology (OMERACT). Dr. Furst has received consultant fees, speaking fees, and/or honoraria (less than $\$ 10,000$ each) from Abbott, Actelion, Amgen, BMS, Biogen Idec, UCB, Gilead, Centocor, GSK, Novartis, Pfizer, NIH, and Roche/ Genentech, and is a member of the Consortium of Rheumatology Researchers of North America (CORRONA). Dr. Curtis has received consultant fees, speaking fees, and/or honoraria (less than $\$ \mathbf{1 0 , 0 0 0}$ each) from Pfizer, BMS, Crescendo, and Abbott, and (more than $\$ 10,000$ each) from Roche, Genentech, UCB, Centocor, CORRONA, and Amgen. Dr. Kavanaugh has conducted clinical research for Centocor, UCB, Genentech/Roche, NIH, Abbott, Takeda, and Amgen. Dr. Kremer has received consultant fees, speaking fees, and/or honoraria (less than $\$ \mathbf{1 0 , 0 0 0}$ each) from Pfizer, BMS, and Amgen, and (more than \$10,000) from Genentech. Dr. Moreland has received consultant fees (less than $\mathbf{\$ 1 0 , 0 0 0}$ ) from Pfizer and is a member of the data safety monitoring board for ChemoCentryx. Dr. Winthrop has received consultant fees, speaking fees, and/or honoraria (less than $\$ 10,000$ each) from Abbott, Amgen, Pfizer, Cellestis, and Wyeth. Dr. Chatham has served as a paid consultant with investment analysts on behalf of Gerson Lehrman and Leerink-Swann. Dr. Bombardier has received honoraria (less than $\$ \mathbf{\$ 1 0 , 0 0 0}$ each) and/or served on the advisory board for Abbott Canada, AstraZeneca, Biogen Idec, BMS, Pfizer (Wyeth), Merck (Schering), Janssen (Merck), and Takeda, and has received honoraria (more than \$10,000 each) from Abbott International and Pfizer. Dr. Dougados has received consultant fees, speaking fees, and/or honoraria (less than \$10,000 each) from Pfizer, Abbott, UCB, BMS, and Roche. Dr. Khanna has received consultant fees, speaking fees, and/or honoraria (less than \$10,000 each) from Genentech, UCB, Pfizer, Actelion, and Gilead. Ms Leong has received consultant fees, speaking fees, and/or honoraria (more than \$10,000 each) from Centocor Ortho Biotech and GlaxoSmithKline. Dr. Kolba owns stock and/or stock options in Merck, Amgen, apies, the ACR commissioned an update of the 2008 recommendations in select topic areas.

The 2012 revision updates the 2008 ACR recommendations in the following areas: 1) indications for DMARDs and biologic agents, 2) switching between DMARD and biologic therapies, 3) use of biologic agents in high-risk patients (those with hepatitis, congestive heart failure [CHF], and malignancy), 4) screening for TB in patients starting or currently receiving biologic agents, and 5) vaccination in patients starting or currently receiving DMARDs or biologic agents (Table 1).

\section{Materials and Methods}

We utilized the same methodology as described in detail in the 2008 guidelines (1) to maintain consistency and to allow cumulative evidence to inform this 2012 recommendations update. These recommendations were developed by 2 expert panels: 1) a nonvoting working group and Core Expert Panel (CEP) of clinicians and methodologists responsible for the selection of the relevant topic areas to be considered, the systematic literature review, the evidence synthesis, and creation of "clinical scenarios"; and 2) a Task Force Panel (TFP) of 11 internationally recognized expert clinicians, patient representatives, and methodologists with expertise in RA treatment, evidence-based medicine, and patient preferences who were tasked with rating

and Genentech. Dr. Saag has received consultant fees, speaking fees, and/or honoraria (less than $\$ 10,000$ each) from Merck, Lilly, Novartis, Genentech, Horizon, and URL, and (more than \$10,000) from Amgen.

Members of the Task Force Panel: Claire Bombardier, MD, MSc (University of Toronto, Toronto, Ontario, Canada), Arthur F. Kavanaugh, MD (University of California, San Diego), Dinesh Khanna, MD, MSc (University of Michigan, Ann Arbor), Joel M. Kremer, MD (Albany Medical Center, Albany, NY), Amye L. Leong, MBA (Healthy Motivation, Santa Barbara, CA), Eric L. Matteson, MD, MPH (Mayo Clinic, Rochester, MN), John T. Schousboe, MD, PhD (Park Nicollet Clinic and University of Minnesota, Minneapolis), Charles M. King, MD (North Mississippi Medical Center, Tupelo), Maxime Dougados, MD (Hôpital Cochin, Paris, France), Eileen Moynihan, MD (Highmark Medicare Services, Woodbury, NJ), Karen S. Kolba, MD (Pacific Arthritis Center, Santa Maria, CA).

Members of the Core Expert Panel: Timothy Beukelman, MD, MSCE, S. Louis Bridges Jr., MD, PhD, W. Winn Chatham, MD, Jeffrey R. Curtis, MD, MPH, Kenneth G. Saag, MD, MSc, Jasvinder A. Singh, MBBS, MPH (University of Alabama at Birmingham), Daniel E. Furst, MD, Harold E. Paulus, MD (University of California, Los Angeles), Ted Mikuls, MD, MSPH (participated in meetings only prior to June 2010; University of Nebraska, Omaha), Larry W. Moreland, MD (University of Pittsburgh, Pittsburgh, PA), James O'Dell, MD (University of Nebraska, Omaha), Maria Suarez-Almazor, MD, MPH (MD Anderson Cancer Center, Houston, TX).

Content-Specific Expert Advisors: Kevin L. Winthrop, MD, MPH (tuberculosis; Oregon Health and Science University, Portland), Michael Saag, MD (infections; University of Alabama at Birmingham).

Address correspondence to Jasvinder A. Singh, MBBS, MPH, University of Alabama at Birmingham, Faculty Office Tower 805B, 510 20th Street South, Birmingham, AL 35294. E-mail: Jasvinder.md@gmail.com.

Submitted for publication May 27, 2011; accepted in revised form February 8, 2012. 
Table 1. Overview comparison of topics and medications included in the 2008 and 2012 American College of Rheumatology rheumatoid arthritis recommendations*

\begin{tabular}{|c|c|c|}
\hline Topic area considered & 2008 & 2012 \\
\hline $\begin{array}{l}\text { Indications for starting or resuming } \\
\text { DMARDs and biologic agents }\end{array}$ & $\sqrt{ }$ & $\sqrt{ }$ \\
\hline \multirow{6}{*}{ DMARDs included +} & 1. Hydroxychloroquine & 1. Hydroxychloroquine \\
\hline & 2. Leflunomide & 2. Leflunomide \\
\hline & 3. Methotrexate & 3. Methotrexate \\
\hline & 4. Minocycline & 4. Minocycline \\
\hline & 5. Sulfasalazine & 5. Sulfasalazine \\
\hline & $\begin{array}{l}\text { And, when appropriate, combination } \\
\text { DMARD therapy with } 2 \text { or } 3 \text { DMARDst }\end{array}$ & $\begin{array}{l}\text { And, when appropriate, combination } \\
\text { DMARD therapv with } 2 \text { or } 3 \text { DMARDs }\end{array}$ \\
\hline \multirow[t]{10}{*}{ Biologic agents included§ } & Non-TNF & Non-TNF \\
\hline & 1. Abatacept & 1. Abatacept \\
\hline & 2. Rituximab & 2. Rituximab \\
\hline & Anti-TNF & 3. Tocilizumab \\
\hline & 3. Adalimumab & Anti-TNF \\
\hline & 4. Etanercept & 4. Adalimumab \\
\hline & 5. Infliximab & 5. Etanercept \\
\hline & & 6. Infliximab \\
\hline & & 7. Certolizumab pegol \\
\hline & & 8. Golimumab \\
\hline $\begin{array}{l}\text { Role of cost and patient preference in } \\
\text { decision making for biologic } \\
\text { agents }\end{array}$ & $\sqrt{ }$ & See 2008 recommendations II \\
\hline Switching between therapies & Considered, but not addressed in detail & $\sqrt{ }$ \\
\hline $\begin{array}{l}\text { Monitoring of side effects of DMARDs } \\
\text { and biologic agents }\end{array}$ & 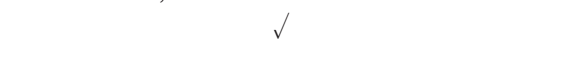 & See 2008 recommendations $\mathbb{I}$ \\
\hline $\begin{array}{l}\text { TB screening for patients starting/ } \\
\text { receiving biologic agents }\end{array}$ & $\checkmark$ & $\sqrt{ }$ \\
\hline $\begin{array}{l}\text { Use of biologic agents in high-risk } \\
\text { patients (those with hepatitis, } \\
\text { congestive heart failure, and } \\
\text { malignancy) }\end{array}$ & $\sqrt{ }$ & 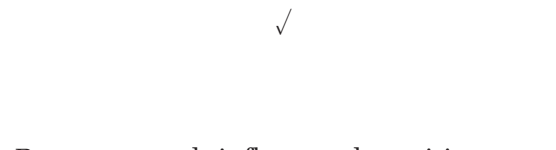 \\
\hline $\begin{array}{l}\text { Vaccinations in patients starting/ } \\
\text { receiving DMARDs or biologic } \\
\text { agents }\end{array}$ & $\begin{array}{l}\text { Pneumococcal, influenza, and hepatitis } \\
\text { vaccines }\end{array}$ & $\begin{array}{l}\text { Pneumococcal, influenza, hepatitis, } \\
\text { human papillomavirus, and herpes } \\
\text { zoster vaccines }\end{array}$ \\
\hline $\begin{array}{l}\text { * DMARDs = disease-modifying antirheuma } \\
\text { + Cyclosporine, azathioprine, and gold were } \\
\text { included in scenarios and the recommendati } \\
\text { ₹ Triple therapy with methotrexate }+ \text { hydrox } \\
\text { § Anakinra was included in the literature sea } \\
\text { II No significant new data related to these to }\end{array}$ & $\begin{array}{l}\text { drugs; non-TNF = non-tumor necrosis factor; } \mathrm{T} \\
\text { cluded in the literature search, but due to the lac } \\
\text { s. } \\
\text { chloroquine }+ \text { sulfasalazine. } \\
\text { h, but due to the lack of new data and/or infreque } \\
\text { s. }\end{array}$ & $\begin{array}{l}\text { tuberculosis. } \\
\text { f new data and/or infrequent use, they were not } \\
\text { se, it was not included in the recommendations. }\end{array}$ \\
\hline
\end{tabular}

the scenarios created using an ordinal scale specified in the RAND/University of California at Los Angeles (RAND/ UCLA) Appropriateness Method (2-4). This method solicited formal input from this multidisciplinary TFP to make recommendations informed by the evidence. The methods used to develop the updated ACR recommendations are described briefly below.

Systematic literature review: sources, databases, and domains. Literature searches for both DMARDs and biologic agents relied predominantly on PubMed searches with medical subject headings and relevant keywords similar to those used for the 2008 ACR RA recommendations (see Supplementary Appendices 1 and 2, available in the online version of this article at http://onlinelibrary.wiley. com/journal/10.1002/(ISSN)2151-4658). We included randomized controlled trials (RCTs), controlled clinical trials, quasi-experimental designs, cohort studies (prospective or retrospective), and case-control studies, with no restrictions on sample size. More details about inclusion criteria are listed below and in Supplementary Appendix 3 (available in the online version of this article at http://online library.wiley.com/journal/10.1002/(ISSN)2151-4658).

The 2008 recommendations were based on a literature search that ended on February 14, 2007. The literature search end date for the 2012 update was February 26, 2010 for the efficacy and safety studies and September 22, 2010 for additional qualitative reviews related to TB screening, immunization, and hepatitis (similar to the 2008 methodology). Studies published subsequent to that date were not included.

For biologic agents, we also reviewed the Cochrane systematic reviews and overviews (published and in press) in the Cochrane Database of Systematic Reviews to identify additional studies (5-8) and further supplemented by hand checking the bibliographies of all included articles. 
Finally, the CEP and TFP confirmed that the relevant literature was included in the evidence synthesis. Unless they were identified by the literature search and met the article inclusion criteria (see Supplementary Appendix 3, available in the online version of this article at http:// onlinelibrary.wiley.com/journal/10.1002/(ISSN)2151-4658), we did not review any unpublished data from product manufacturers, investigators, or the Food and Drug Administration (FDA) Adverse Event Reporting System.

We searched the literature for the 8 DMARDs and 9 biologic agents most commonly used for the treatment of RA. Literature was searched for 8 DMARDs: azathioprine, cyclosporine, hydroxychloroquine, leflunomide, methotrexate, minocycline, organic gold compounds, and sulfasalazine. Similar to 2008, azathioprine, cyclosporine, and gold were not included in the recommendations based on their infrequent use and lack of new data (Table 1). Literature was searched for 9 biologic agents: abatacept, adalimumab, anakinra, certolizumab pegol, etanercept, golimumab, infliximab, rituximab, and tocilizumab. Anakinra was not included in the recommendations due to infrequent use and lack of new data. Details of the bibliographic search strategy are listed in Supplementary Appendix 1 (available in the online version of this article at http://onlinelibrary.wiley.com/journal/10.1002/(ISSN)21514658).

\section{Literature search criteria and article selection.}

Inclusion and exclusion criteria for review of article abstracts and titles. With the exception of assessment of $\mathrm{TB}$, hepatitis, and vaccination (see below), studies were included if they met all of the following criteria: 1) original study in English language with an abstract, 2) observational studies (case-control or cohort) or intervention studies, 3) related to the treatment of RA with DMARDs or biologic agents, and 4) study duration of at least 6 months (see Supplementary Appendix 2, available in the online version of this article at http://onlinelibrary.wiley.com/ journal/10.1002/(ISSN)2151-4658).

Studies were excluded if they met any of the following criteria: 1) the report was a meeting abstract, review article, or meta-analysis; 2) the study duration was less than 6 months; and 3) DMARDs or biologic agents were used for non-RA conditions (e.g., psoriatic arthritis, systematic lupus erythematosus) or non-FDA-approved use in health conditions other than RA (e.g., biologic agents in vasculitis) (see Supplementary Appendix 2, available in the online version of this article at http://onlinelibrary.wiley.com/ journal/10.1002/(ISSN)2151-4658).

Selection criteria for articles reviewing efficacy/adverse events. Two reviewers independently screened the titles and abstracts of the 2,497 potential articles from the PubMed and Cochrane Library searches by applying the above selection method. Any disagreements were resolved by consultation with the lead reviewer (JAS). The lead author also reviewed all titles and abstracts to identify any that might have been overlooked. We identified 149 original articles from the 3 searches for full-text retrieval. After excluding duplicates, 128 unique original articles were identified and the data were abstracted. This included 16 articles focused on DMARDs and 112 on biologic agents (98 on the 6 biologic agents assessed in the 2008 RA recommendations and 14 on certolizumab pegol, golimumab, and tocilizumab, 3 newer biologic agents that had been added since the 2008 recommendations) (see Supplementary Appendix 3, available in the online version of this article at http://onlinelibrary.wiley.com/journal/10.1002/ (ISSN)2151-4658). A list of all included articles is provided in Supplementary Appendix 4 (available in the online version of this article at http://onlinelibrary.wiley. com/journal/10.1002/(ISSN)2151-4658).

Additional literature searches for articles reviewing $T B$ screening, hepatitis, and vaccination. Qualitative reviews of the literature were performed for these 3 topics (completed September 22, 2010). Similar to the strategy for the 2008 recommendations, literature searches were broadened to include case reports and case series of any size, review articles, and meta-analyses, plus inclusion of diseases other than RA. In addition, we included searches on the Centers for Disease Control and Prevention (CDC) web site (www.cdc.gov) for past and current recommendations regarding TB screening and vaccination in immunocompromised patients.

Agreement between reviewers for selection of studies for full-text retrieval. The kappa coefficients (agreement beyond chance) for independent selection of articles for full-text review by the 2 reviewers met or exceeded 0.60 (good) for DMARDs, 0.65 (very good) for the 6 biologic agents included in the 2008 ACR recommendations, and 0.84 (excellent) for a combination of certolizumab pegol, golimumab, and tocilizumab (9).

Full-text article review, data abstraction, data entry, and evidence report generation. The full text of each article was reviewed; data abstraction and entry were performed by reviewers using a standardized Microsoft Access database that was developed and used for data abstraction for the 2008 ACR RA recommendations. Two reviewers were assigned to abstract data on DMARDs (SB, $\mathrm{DEF}$ ), rituximab (HA, ERV), and the rest of the biologic agents ( $\mathrm{AB}, \mathrm{AJ})$. To ensure that the error rates were low and abstractions were similar, 26 articles related to biologic agents were dually abstracted by 2 abstractors (AB, AJ). The data entry errors were less than $3 \%$. Entered data were further checked against raw data on biologic agents from the Cochrane systematic reviews (5-8). Following this comprehensive literature review, we developed an evidence report using the data abstracted from the published studies.

Development of clinical scenarios. Clinical scenarios were drafted by the investigators and the CEP, based on the updated evidence report. We used the same key determinant clinical thresholds and treatment decision branch points that were developed for the 2008 ACR RA treatment recommendations (1). Clinical scenarios were constructed based on permutations in the particular therapeutic considerations that reflected: 1) disease duration (early versus established RA), 2) disease activity (low, moderate, or high) (Tables 2 and 3 and Supplementary Appendix 5, available in the online version of this article at http:// onlinelibrary.wiley.com/journal/10.1002/(ISSN)2151-4658), 
Table 2. Definitions of key terms and key assumptions for clinical scenarios for the 2012 ACR recommendations update for the treatment of $\mathrm{RA}^{*}$

\begin{tabular}{|c|c|}
\hline & Definitions \\
\hline \multicolumn{2}{|l|}{ KEY TERMS } \\
\hline DMARDst & Hydroxychloroquine, leflunomide, methotrexate, minocycline, or sulfasalazine \\
\hline Non-methotrexate DMARDs & Hydroxychloroquine, leflunomide, minocycline, or sulfasalazine \\
\hline $\begin{array}{l}\text { DMARD combination } \\
\text { therapy }\end{array}$ & $\begin{array}{l}\text { Combinations including } 2 \text { drugs, most of which are methotrexate based, with only a few } \\
\text { exceptions (e.g., methotrexate + hydroxychloroquine, methotrexate + leflunomide, } \\
\text { methotrexate + sulfasalazine, sulfasalazine + hydroxychloroquine), and triple therapy } \\
\text { (methotrexate + hydroxychloroquine }+ \text { sulfasalazine) }\end{array}$ \\
\hline Anti-TNF biologics & Adalimumab, certolizumab pegol, etanercept, infliximab, or golimumab \\
\hline Non-TNF biologics & Abatacept, rituximab, or tocilizumab \\
\hline Biologic agents & Anti-TNF biologic or non-TNF biologic (8 biologic agents, excluding anakinra) \\
\hline Early RA & RA disease duration $<6$ months \\
\hline Established RA & RA disease duration $\geq 6$ months or meeting the 1987 ACR classification criteria (24)‡ \\
\hline Disease activity & $\begin{array}{l}\text { Categorized as low, moderate, and high as per validated common scales (Table } 3 \text { and } \\
\text { Supplementary Appendix 4, available in the online version of this article at http:// } \\
\text { onlinelibrary.wiley.com/journal/10.1002/(ISSN)2151-4658) or the treating clinician's formal } \\
\text { assessment (26-32) }\end{array}$ \\
\hline Poor prognosis & $\begin{array}{l}\text { Presence of } 1 \text { or more of the following features: functional limitation (e.g., HAQ DI or similar } \\
\text { valid tools), extraarticular disease (e.g., presence of rheumatoid nodules, RA vasculitis, } \\
\text { Felty's syndrome), positive rheumatoid factor or anti-cyclic citrullinated peptide antibodies } \\
\text { (33-37), or bony erosions by radiograph (38-40) }\end{array}$ \\
\hline RA remission & $\begin{array}{l}\text { A joint ACR/EULAR task force defined remission as a tender joint count, swollen joint count, } \\
\text { C-reactive protein (mg/dl) level, and patient global assessment of } \leq 1 \text { each or a simplified } \\
\text { Disease Activity Score of } \leq 3.3(41)\end{array}$ \\
\hline Child-Pugh classification & $\begin{array}{l}\text { Scoring system based upon the levels of albumin, total bilirubin, and prothrombin time, and } \\
\text { the presence of ascites and encephalopathy. Patients with a score of } 10 \text { or more (in the class } \\
\mathrm{C} \text { category) have a prognosis with a 1-year survival rate of } \sim 50 \% \text {. Patients with class A or B } \\
\text { have a better 5-year prognosis, with a survival rate of } 70-80 \% \text { (12) }\end{array}$ \\
\hline NYHA class III and IV & $\begin{array}{l}\text { NYHA class III includes patients with cardiac disease resulting in marked limitation of } \\
\text { physical activity with less than ordinary physical activity causing fatigue, palpitation, } \\
\text { dyspnea, or anginal pain, but no symptoms at rest. NYHA class IV includes patients with } \\
\text { cardiac disease resulting in inability to carry on any physical activity without discomfort } \\
\text { and symptoms of cardiac insufficiency or that the anginal syndrome may be present even at } \\
\text { rest, which increases if any physical activity is undertaken (13) }\end{array}$ \\
\hline $\begin{array}{l}\text { CDC-defined risk factors for } \\
\text { latent TB infection }\end{array}$ & $\begin{array}{l}\text { Close contacts of persons known or suspected to have active TB; foreign-born persons from } \\
\text { areas with a high incidence of active TB (e.g., Africa, Asia, Eastern Europe, Latin America, } \\
\text { and Russia); persons who visit areas with a high prevalence of active TB, especially if visits } \\
\text { are frequent or prolonged; residents and employees of congregate settings whose clients are } \\
\text { at an increased risk for active TB (e.g., correctional facilities, long-term care facilities, and } \\
\text { homeless shelters); health care workers who serve clients who are at an increased risk for } \\
\text { active TB; populations defined locally as having an increased incidence of latent } \\
\text { Mycobacterium tuberculosis infection or active TB, possibly including medically } \\
\text { underserved, low-income populations, or persons who abuse drugs or alcohol; and infants, } \\
\text { children, and adolescents exposed to adults who are at an increased risk for latent } M \\
\text { tuberculosis infection or active TB (14) }\end{array}$ \\
\hline \multicolumn{2}{|l|}{ KEY ASSUMPTIONS } \\
\hline & 1. Focus on common patients, not exceptional cases \\
\hline & 2. Cost not considered; please see 2008 recommendations (1) \\
\hline & 3. Alternate therapeutic choices taken into account \\
\hline & \\
\hline & $\begin{array}{l}\text { Supplementary Appendix 6, available in the online version of this article at http:// } \\
\text { onlinelibrary.wiley.com/journal/10.1002/(ISSN)2151-4658)§ }\end{array}$ \\
\hline & $\begin{array}{l}\text { 6. Optimal dose of medication (as defined by the treating clinician) given for } 3 \text { months (in lieu } \\
\text { of total duration of therapy) before therapy escalation or switching }\end{array}$ \\
\hline & 7. Disease activity and prognosis assessments performed between 3 and 6 months after \\
\hline & $\begin{array}{l}\text { 8. Assume that a clinical indication exists (based upon disease activity) for use of each treatment } \\
\text { option }\end{array}$ \\
\hline \multicolumn{2}{|c|}{$\begin{array}{l}\text { * ACR = American College of Rheumatology; RA = rheumatoid arthritis; DMARDs = disease-modifying antirheumatic drugs; anti-TNF = anti-tumor } \\
\text { necrosis factor; HAQ = Health Assessment Questionnaire; DI = disability index; EULAR = European League Against Rheumatism; NYHA = New York } \\
\text { Heart Association; CDC = Centers for Disease Control and Prevention; TB = tuberculosis. } \\
\text { † Azathioprine, cyclosporine, and gold were considered but not included due to their infrequent use in RA and/or the lack of new data since } 2008 \text {. } \\
\text { † New classification criteria for RA (ACR/EULAR collaborative initiative) have been published (23); however, the evidence available for these } 2011 \\
\text { recommendations relied on the use of the } 1987 \text { ACR RA classification criteria, since literature review preceded the publication of the new criteria. We } \\
\text { anticipate that in the near future, data using the new classification criteria may be available for evidence synthesis and formulating recommendations. } \\
\text { § Agreement as defined by the RAND/UCLA Appropriateness Method. }\end{array}$} \\
\hline
\end{tabular}




\begin{tabular}{|cl|}
\hline $\begin{array}{c}\text { Table 3. Instruments to measure rheumatoid arthritis disease activity and to } \\
\text { define remission }\end{array}$ & \multicolumn{1}{c|}{$\begin{array}{c}\text { Thresholds of disease } \\
\text { activity levels }\end{array}$} \\
\hline Instrument & \multicolumn{1}{c|}{$\begin{array}{c}\text { Remission: } 0-0.25 \\
\text { Low activity: } 0.26-3.7\end{array}$} \\
\hline $\begin{array}{c}\text { Patient Activity Scale (PAS) or PAS-II } \\
\text { (range 0-10) (31) }\end{array}$ & Moderate activity: 3.71 to $<8.0$ \\
& High activity: $\geq 8.0$ \\
Routine Assessment of Patient Index & Remission: $0-1.0$ \\
Data 3 (range 0-10) (42) & Low activity: $>1.0$ to 2.0 \\
& Moderate activity: $>2.0$ to 4.0 \\
Clinical Disease Activity Index (range & High activity: $>4.0$ to 10 \\
0-76.0) (43) & Remission: $\leq 2.8$ \\
& Low activity: $>2.8$ to 10.0 \\
& Moderate activity: $>10.0$ to 22.0 \\
Disease Activity Score in 28 joints & High activity: $>22$ \\
(range 0-9.4) (44) & Remission: $<2.6$ \\
& Low activity: $\geq 2.6$ to $<3.2$ \\
Simplified Disease Activity Index & Moderate activity: $\geq 3.2$ to $\leq 5.1$ \\
(range 0-86.0) (45) & High activity: $>5.1$ \\
& Remission: $\leq 3.3$ \\
& Low activity: $>3.3$ to $\leq 11.0$ \\
& Moderate activity: $>11.0$ to $\leq 26$ \\
& High activity: $>26$ \\
\hline
\end{tabular}

3) current medication regimen, and 4) presence of poor prognostic factors (yes or no, as defined in the 2008 ACR recommendations). An example of a clinical scenario is: "The patient has active established RA and has failed an adequate trial of an Anti-TNF [anti-tumor necrosis factor] biologic because of adverse events. Is it appropriate to switch to another Anti-TNF biologic after failing etanercept?" (see Supplementary Appendix 6, available in the online version of this article at http://onlinelibrary.wiley. com/journal/10.1002/(ISSN)2151-4658). Scenarios included both new considerations and questions considered in the 2008 recommendations.

For this 2012 update, we used a modified Delphi process and obtained consensus (defined as $\geq 70 \%$ agreement) from the CEP for inclusion of relevant clinical scenarios based on 1) review of each of the previous 2008 scenarios and 2) review of newly developed scenarios to address switching between therapies. We provided CEP members with manuscript abstracts and requested full-text articles to help inform decisions.

The CEP members also recommended the following: 1) use of the FDA definitions of "serious" and "non-serious" adverse events (10), 2) exclusion of 3 DMARDs used very infrequently (i.e., cyclosporine, azathioprine, and gold; see above) or without additional relevant new data, and 3) exclusion of 1 biologic agent without additional relevant new evidence and with infrequent use (anakinra).

Rating the appropriateness of clinical scenarios by the TFP. The TFP is referred to as the "panel" in the Methods and the recommendations that follow. For the first round of ratings we contacted panel members by e-mail and provided them with the evidence report, clinical scenarios, and rating instructions. We asked them to use the evidence report and their clinical judgment to rate the "appropriateness" of the clinical scenarios under consideration. The panelists individually rated each scenario permutation using a 9-point Likert appropriateness scale. A median score of 1 to 3 indicated "not appropriate" and 7 to 9 indicated "appropriate" for taking action defined in the scenario (2-4). For all eventual recommendations, the RAND/UCLA appropriateness panel score required a median rating of 7 to 9 . Those scenario permutations with median ratings in the 4 to 6 range and those with disagreement among the panelists (i.e., one-third or more TFP members rating the scenario in the 1 to 3 range and onethird or more rating it in the 7 to 9 range) were classified as "uncertain." At a face-to-face meeting with both the TFP and the CEP members on November 15, 2010, the anonymous first round of ratings by the panel, including dispersion of the scores, ranges, and median scores, was provided to the task force panelists.

The task force panelists agreed upon certain assumptions and qualifying statements on which they based their discussion and subsequent ratings of the scenarios (Table 2). A second round of ratings by panel members occurred after extensive in-person discussion of the prior ratings and review of the evidence supporting each scenario.

Conversion of clinical scenarios to ACR RA treatment recommendations. After the TFP meeting was complete, recommendations were derived from directly transcribing the final clinical scenario ratings. Based on the ratings, scenario permutations were collapsed to yield the most parsimonious recommendations. For example, when ratings favored a drug indication for both moderate and high disease activity, one recommendation was given, specifying "moderate or high disease activity." In most circumstances, the recommendations included only positive and not negative statements. For example, the recommenda- 
tions focused on when to initiate specific therapies rather than when an alternate therapy should not be used. Most of the recommendations were formulated by drug category (DMARD, anti-TNF biologic, non-TNF biologic listed alphabetically within category), since in many instances, the ratings were similar for medications within a drug category. We specifically note instances where a particular medication was recommended but others in its group were not endorsed. Two additional community-based rheumatologists independently reviewed the manuscript and provided comments. CEP and TFP members reviewed and approved all final recommendations.

For each final recommendation, the strength of evidence was assigned using the methods from the American College of Cardiology (11). Three levels of evidence were specified: 1) level of evidence A: data were derived from multiple RCTs; 2) level of evidence B: data were derived from a single randomized trial or nonrandomized studies; and 3) level of evidence C: data were derived from consensus opinion of experts, case studies, or standards of care. The evidence was rated by 4 panel experts (JO and JMK, AFK and LWM, where each rated half of the evidence), and discrepancies were resolved by consensus.

Level C evidence often denoted a circumstance where medical literature addressed the general topic under discussion but it did not address the specific clinical situations or scenarios reviewed by the panel. Since many recommendations had multiple components (in most cases, multiple medication options), a range is sometimes provided for the level of evidence; for others, the level of evidence is provided following each recommendation.

ACR peer review of recommendations. Following construction of the recommendations, the manuscript was reviewed through the regular journal review process and by more than 30 ACR members serving on the ACR Guidelines Subcommittee, ACR Quality of Care Committee, and ACR Board of Directors.

\section{Recommendations for the Use of DMARDs and Biologic Agents in Patients Who Qualify for Treatment of RA}

This 2012 ACR recommendations update incorporates the evidence from systematic literature review synthesis and recommendations from 2008 (1) and rates updated and new clinical scenarios regarding the use of DMARDs and biologic agents for the treatment of RA. Terms used in the recommendations are defined in Table 2. The 2012 recommendations are listed in the 4 sections below and in the following order:

1. Indications for and switching DMARDs and biologic agents: early RA (indications, Figure 1) followed by established RA (indications and switching, Figure 2), along with details of the level of evidence supporting these recommendations (see Supplementary Appendix 7 , available in the online version of this article at http://onlinelibrary.wiley.com/journal/10.1002/(ISSN) 2151-4658)

2. Use of biologic agents in patients with hepatitis, malignancy, or CHF who qualify for RA management (Table 4)
3. Screening for TB in patients starting or currently receiving biologic agents as part of their RA therapy (Figure 3)

4. Vaccination in patients starting or currently receiving DMARDs or biologic agents as part of their RA therapy (Table 5)

In the figures, decision points are shown as diamonds and actions to be taken by the health care provider are shown as rectangles. The recommendations in the text below and in Tables 4 and 5 represent the results of the 2012 update only, whereas Figures 1-3 also incorporate some of the 2008 ACR RA recommendations that did not change (1). Areas of uncertainty by the panel (that did not lead to recommendations) are noted in Supplementary Appendix 8 (available in the online version of this article at http://onlinelibrary.wiley.com/journal/10.1002/(ISSN) 2151-4658).

1. Indications for starting, resuming, adding, or switching DMARDs or biologic agents. We first describe a recommendation targeting remission or low disease activity in RA (section 1A). This is followed by recommendations for DMARD or biologic agent use in early RA (section 1B). Next, we provide recommendations for initiating and switching between DMARDs and biologic agents in established RA (section 1C).

1A. Target low disease activity or remission. The panel recommends targeting either low disease activity (Table 3) or remission (Table 2) in all patients with early RA (Figure 1; level of evidence $\mathrm{C}$ ) and established RA (Figure 2; level of evidence $\mathrm{C}$ ) receiving any DMARD or biologic agent.

1B. Early RA (disease duration $<6$ months). In patients with early RA, the panel recommends the use of DMARD monotherapy both for low disease activity and for moderate or high disease activity with the absence of poor prognostic features (Figure 1; level of evidence A-C) (details are shown in Supplementary Appendix 7, available in the online version of this article at http://onlinelibrary.wiley. com/journal/10.1002/(ISSN)2151-4658).

In patients with early RA, the panel recommends the use of DMARD combination therapy (including double and triple therapy) in patients with moderate or high disease activity plus poor prognostic features (Figure 1; level of evidence $\mathrm{A}-\mathrm{C}$ ).

In patients with early RA, the panel also recommends the use of an anti-TNF biologic with or without methotrexate in patients who have high disease activity with poor prognostic features (Figure 1; level of evidence A and B). Infliximab is the only exception and the recommendation is to use it in combination with methotrexate, but not as monotherapy.

1C. Established $R A$ (disease duration $\geq 6$ months or meeting the 1987 ACR RA classification criteria). The remainder of panel recommendations regarding indications for DMARDs and biologic agents are for patients with established RA. The 3 subsections below define recommendations for initiating and switching therapies in established RA (Figure 2). Where the prognosis is not mentioned, the recommendation to use/switch to a DMARD or a biologic agent applies to all patients, regardless of prognostic features. 


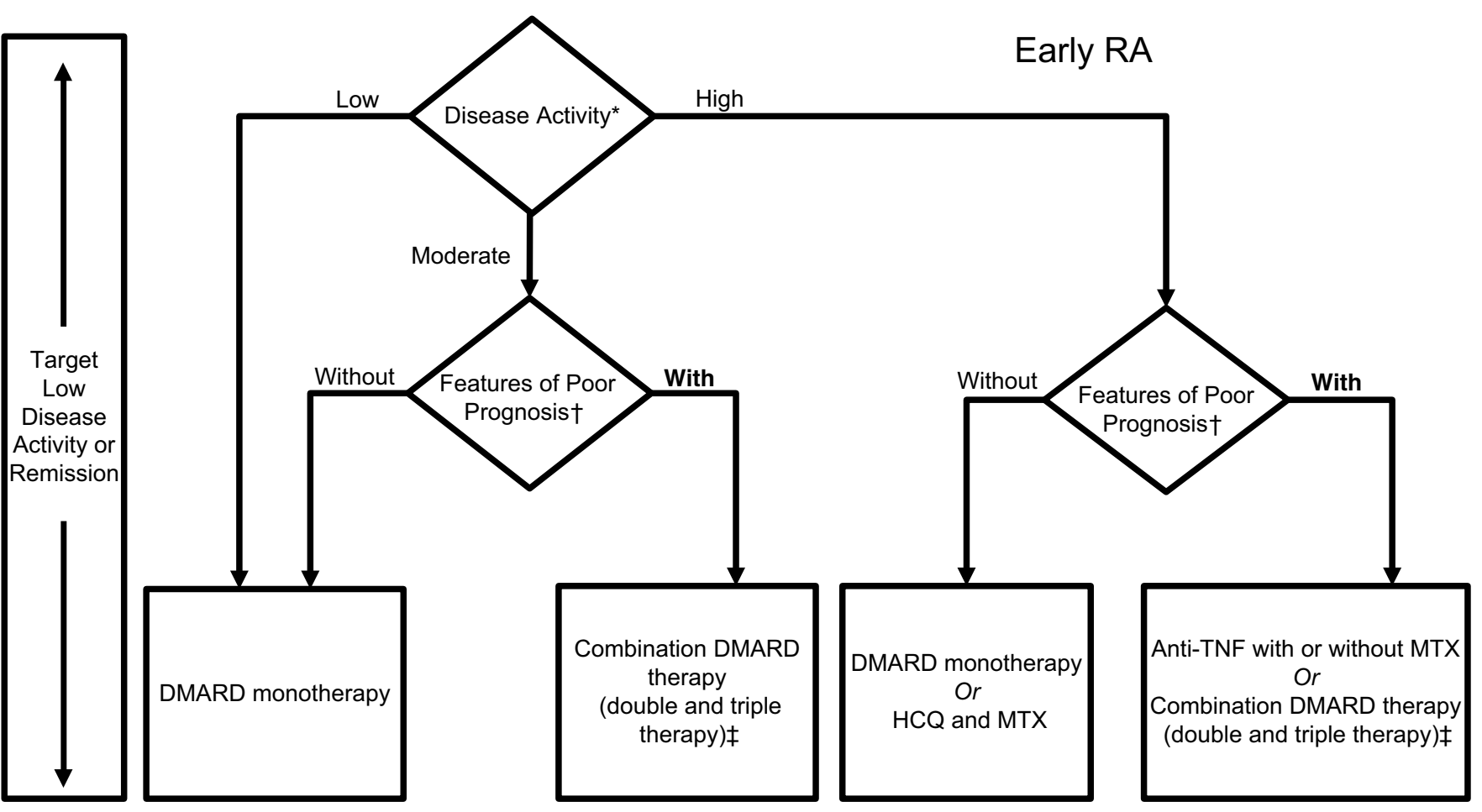

Figure 1. 2012 American College of Rheumatology recommendations update for the treatment of early rheumatoid arthritis (RA), defined as a disease duration $<\mathbf{6}$ months. For the level of evidence supporting each recommendation, please see Supplementary Appendix 7 (available in the online version of this article at http://onlinelibrary.wiley.com/journal/10.1002/(ISSN)2151-4658). DMARD = diseasemodifying antirheumatic drug (includes hydroxychloroquine [HCQ], leflunomide [LEF], methotrexate [MTX], minocycline, and sulfasalazine); anti-TNF = anti-tumor necrosis factor.

* Definitions of disease activity are discussed in Tables 2 and 3 and Supplementary Appendix 4 (available in the online version of this article at http://onlinelibrary.wiley.com/journal/10.1002/(ISSN)2151-4658) and were categorized as low, moderate, or high.

+ Patients were categorized based on the presence or absence of 1 or more of the following poor prognostic features: functional limitation (e.g., Health Assessment Questionnaire score or similar valid tools), extraarticular disease (e.g., presence of rheumatoid nodules, RA vasculitis, Felty's syndrome), positive rheumatoid factor or anti-cyclic citrullinated peptide antibodies (33-37), and bony erosions by radiograph (38).

¥ Combination DMARD therapy with 2 DMARDs, which is most commonly MTX based, with some exceptions (e.g., MTX + HCQ, MTX + LEF, MTX + sulfasalazine, and sulfasalazine + HCQ), and triple therapy (MTX + HCQ + sulfasalazine) as defined in Table 2.

Initiating and switching among DMARDs.

If after 3 months of DMARD monotherapy (in patients without poor prognostic features), a patient deteriorates from low to moderate/high disease activity, then methotrexate, hydroxychloroquine, or leflunomide should be added (rectangle A of Figure 2; level of evidence A and B).

If after 3 months of methotrexate or methotrexate/ DMARD combination, a patient still has moderate or high disease activity, then add another non-methotrexate DMARD or switch to a different non-methotrexate DMARD (rectangle B of Figure 2; level of evidence B and C).

Switching from DMARDs to biologic agents.

If a patient has moderate or high disease activity after 3 months of methotrexate monotherapy or DMARD combination therapy, as an alternative to the DMARD recommendation just noted above, the panel recommends adding or switching to an anti-TNF biologic, abatacept, or rituximab (rectangles $\mathrm{C}$ and D of Figure 2; level of evidence A-C).

If after 3 months of intensified DMARD combination therapy or after a second DMARD, a patient still has moderate or high disease activity, add or switch to an anti-TNF biologic (rectangle C of Figure 2; level of evidence C).
Switching among biologic agents due to lack of benefit or loss of benefit.

If a patient still has moderate or high disease activity after 3 months of anti-TNF biologic therapy and this is due to a lack or loss of benefit, switching to another anti-TNF biologic or a non-TNF biologic is recommended (rectangles F and G of Figure 2; level of evidence B and C).

If a patient still has moderate or high disease activity after 6 months of a non-TNF biologic and the failure is due to a lack or loss of benefit, switch to another non-TNF biologic or an anti-TNF biologic (rectangles $\mathrm{F}$ and $\mathrm{G}$ of Figure 2; level of evidence B and C). An assessment period of 6 months was chosen rather than 3 months, due to the anticipation that a longer time may be required for efficacy of a non-TNF biologic.

Switching among biologic agents due to harms/adverse events.

If a patient has high disease activity after failing an anti-TNF biologic because of a serious adverse event, switch to a non-TNF biologic (rectangle E of Figure 2; level of evidence C).

If a patient has moderate or high disease activity after failing an anti-TNF biologic because of a nonserious ad- 


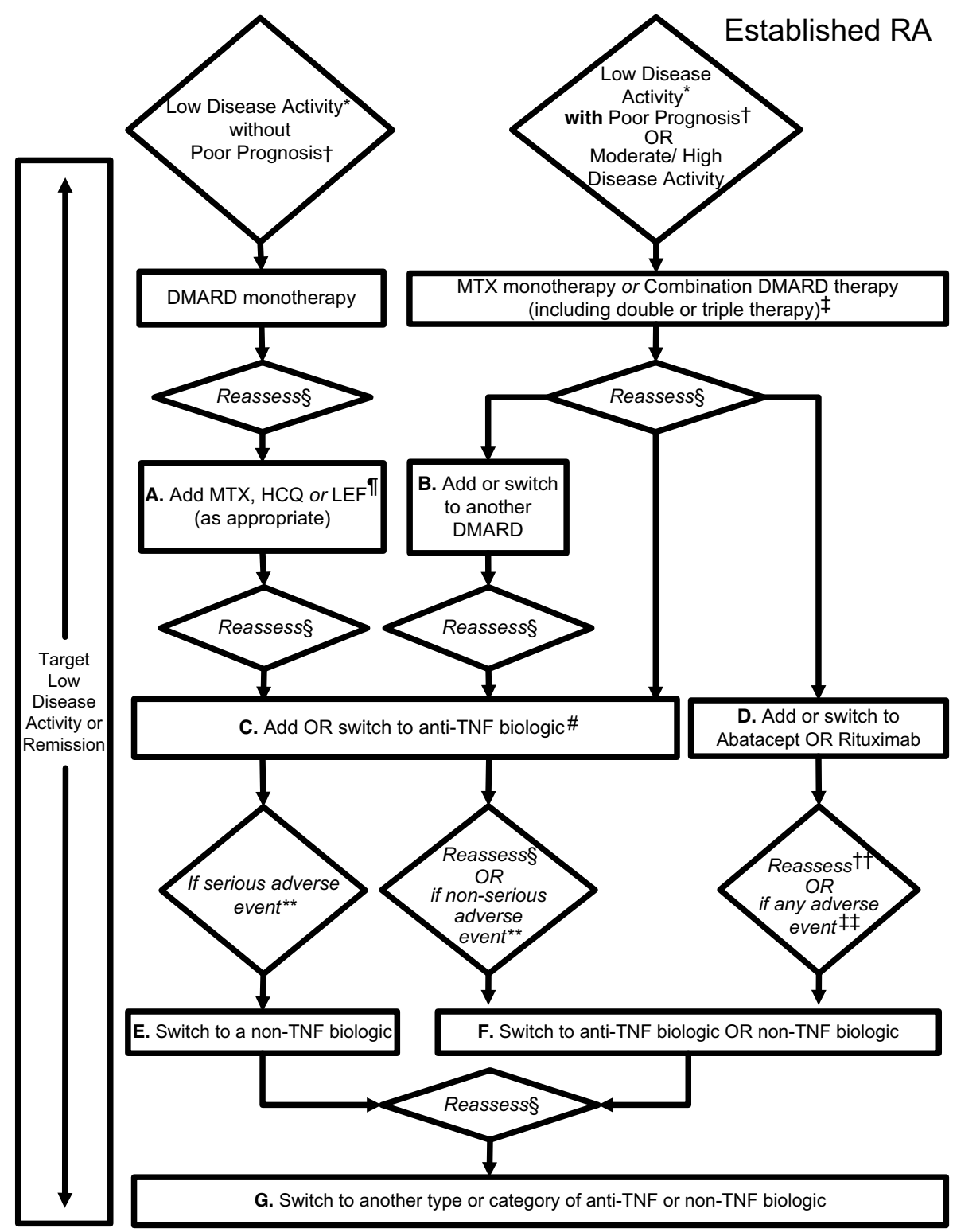

Figure 2. 2012 American College of Rheumatology (ACR) recommendations update for the treatment of established rheumatoid arthritis (RA), defined as a disease duration $\geq 6$ months or meeting the 1987 ACR classification criteria. Depending on a patient's current medication regimen, the management algorithm may begin at an appropriate rectangle in the figure, rather than only at the top of the figure. Disease-modifying antirheumatic drugs (DMARDs) include hydroxychloroquine (HCQ), leflunomide (LEF), methotrexate (MTX), minocycline, and sulfasalazine (therapies are listed alphabetically; azathioprine and cyclosporine were considered but not included). DMARD monotherapy refers to treatment in most instances with HCQ, LEF, MTX, or sulfasalazine; in few instances, where appropriate, minocycline may also be used. Anti-tumor necrosis factor (anti-TNF) biologics include adalimumab, certolizumab pegol, etanercept, infliximab, and golimumab. Non-TNF biologics include abatacept, rituximab, or tocilizumab (therapies are listed alphabetically). For the level of evidence supporting each recommendation, please see Supplementary Appendix 7 (available in the online version of this article at http://onlinelibrary.wiley.com/journal/10.1002/(ISSN)2151-4658).

${ }^{*}$ Definitions of disease activity are discussed in Tables 2 and 3 and Supplementary Appendix 4 (available in the online version of this article at http://onlinelibrary.wiley.com/journal/10.1002/(ISSN)2151-4658) and were categorized as low, moderate, or high.

† Features of poor prognosis included the presence of 1 or more of the following: functional limitation (e.g., Health Assessment Questionnaire score or similar valid tools), extraarticular disease (e.g., presence of rheumatoid nodules, RA vasculitis, Felty's syndrome), positive rheumatoid factor or anti-cyclic citrullinated peptide antibodies (33-37), and bony erosions by radiograph (38).

‡ Combination DMARD therapy with 2 DMARDs, which is most commonly MTX based, with few exceptions (e.g., MTX + HCQ, MTX + LEF, MTX + sulfasalazine, sulfasalazine + HCQ), and triple therapy (MTX + HCQ + sulfasalazine).

§ Reassess after 3 months and proceed with escalating therapy if moderate or high disease activity in all instances except after treatment with a non-TNF biologic (rectangle D), where reassessment is recommended at 6 months due to a longer anticipated time for peak effect.

I LEF can be added in patients with low disease activity after 3-6 months of minocycline, HCQ, MTX, or sulfasalazine.

\# If after 3 months of intensified DMARD combination therapy or after a second DMARD has failed, the option is to add or switch to an anti-TNF biologic.

** Serious adverse events were defined per the US Food and Drug Administration (FDA; see below); all other adverse events were considered nonserious adverse events.

t+ Reassessment after treatment with a non-TNF biologic is recommended at 6 months due to anticipation that a longer time to peak effect is needed for non-TNF compared to anti-TNF biologics.

¥¥ Any adverse event was defined as per the US FDA as any undesirable experience associated with the use of a medical product in a patient. The FDA definition of serious adverse event includes death, life-threatening event, initial or prolonged hospitalization, disability, congenital anomaly, or an adverse event requiring intervention to prevent permanent impairment or damage. 
Table 4. 2012 American College of Rheumatology recommendations update for the use of biologic agents in patients otherwise qualifying for the rheumatoid arthritis treatment with a history of hepatitis, malignancy, or congestive heart failure*

\begin{tabular}{|c|c|c|c|}
\hline Comorbidity/clinical circumstance & Recommended & Not recommended & $\begin{array}{r}\text { Level of } \\
\text { evidence }\end{array}$ \\
\hline \multicolumn{4}{|l|}{ Hepatitis } \\
\hline Hepatitis C & Etanercept & & C \\
\hline $\begin{array}{l}\text { Untreated chronic hepatitis B or with treated chronic } \\
\text { hepatitis B with Child-Pugh class B and highert }\end{array}$ & & Any biologic agent & $\mathrm{C}$ \\
\hline \multicolumn{4}{|l|}{ Malignancy } \\
\hline $\begin{array}{l}\text { Treated solid malignancy }>5 \text { years ago or treated } \\
\text { nonmelanoma skin cancer }>5 \text { years ago }\end{array}$ & Any biologic agent & & $\mathrm{C}$ \\
\hline $\begin{array}{l}\text { Treated solid malignancy within the last } 5 \text { years or } \\
\text { treated nonmelanoma skin cancer within the last } 5 \\
\text { yearsł }\end{array}$ & Rituximab & & $\mathrm{C}$ \\
\hline Treated skin melanoma $\ddagger$ & Rituximab & & $\mathrm{C}$ \\
\hline Treated lymphoproliferative malignancy & Rituximab & & $\mathrm{C}$ \\
\hline \multicolumn{4}{|l|}{ Congestive heart failure } \\
\hline $\begin{array}{l}\text { NYHA class III/IV and with an ejection fraction of } \\
\leq 50 \% \S\end{array}$ & & Anti-TNF biologic & $\mathrm{C}$ \\
\hline \multicolumn{4}{|c|}{$\begin{array}{l}\text { * For definitions and key terms, please refer to Table } 2 \text {. NYHA }=\text { New York Heart Association; anti-TNF }=\text { anti-tumor necrosis factor. } \\
+ \text { Therapy defined as an antiviral regimen deemed appropriate by an expert in liver diseases. The Child-Pugh classification liver disease scoring system } \\
\text { is based on the presence of albumin, ascites, total bilirubin, prothrombin time, and encephalopathy. Patients with a score of } 10 \text { or more (in the class } \\
\text { C category) have a prognosis with 1-year survival being } \sim 50 \% \text {. Patients with class A or B have a better prognosis of } 5 \text { years, with a survival rate of } \\
70-80 \% \text { (12). } \\
\text { ₹ Little is known about the effects of biologic therapy on solid cancers treated within the past } 5 \text { years, due to exclusion of these patients from most } \\
\text { randomized controlled trials. } \\
\text { § NYHA class III = patients with cardiac disease resulting in marked limitation of physical activity. They are comfortable at rest. Less than ordinary } \\
\text { physical activity causes fatigue, palpitation, dyspnea, or anginal pain. NYHA class IV = patients with cardiac disease resulting in inability to carry out } \\
\text { any physical activity without discomfort. Symptoms of cardiac insufficiency or of anginal syndrome may be present even at rest. If any physical activity } \\
\text { is undertaken, discomfort is increased (13). }\end{array}$} \\
\hline
\end{tabular}

verse event, switch to another anti-TNF biologic or a nonTNF biologic (rectangle F of Figure 2; level of evidence B and C).

If a patient has moderate or high disease activity after failing a non-TNF biologic because of an adverse event (serious or nonserious), switch to another non-TNF biologic or an anti-TNF biologic (rectangle F of Figure 2; level of evidence $\mathrm{C}$ ).

2. Use of biologic agents in RA patients with hepatitis, malignancy, or CHF, qualifying for more aggressive treatment (level of evidence $\mathrm{C}$ for all recommendations).

Hepatitis $B$ or $C$. The panel recommends that etanercept could potentially be used in RA patients with hepatitis $C$ requiring $R A$ treatment (Table 4 ).

The panel also recommends not using biologic agents in RA patients with untreated chronic hepatitis B (disease not treated due to contraindications to treatment or intolerable adverse events) and in RA patients with treated chronic hepatitis B with Child-Pugh class B and higher (Table 4; for details of Child-Pugh classification, see Table 2) (12). The panel did not make recommendations regarding the use of any biologic agent for treatment in RA patients with a history of hepatitis $B$ and a positive hepatitis B core antibody.

Malignancies. For patients who have been treated for solid malignancies more than 5 years ago or who have been treated for nonmelanoma skin cancer more than 5 years ago, the panel recommends starting or resuming any biologic agent if those patients would otherwise qualify for this RA management strategy (Table 4).
The panel only recommends starting or resuming rituximab in RA patients with: 1) a previously treated solid malignancy within the last 5 years, 2) a previously treated nonmelanoma skin cancer within the last 5 years, 3) a previously treated melanoma skin cancer, or 4) a previously treated lymphoproliferative malignancy. Little is known about the effects of biologic therapy in patients with a history of a solid cancer within the past 5 years owing to the exclusion of such patients from participation in clinical trials and the lack of studies examining the risk of recurrent cancer in this subgroup of patients.

CHF. The panel recommends not using an anti-TNF biologic in RA patients with CHF that is New York Heart Association (NYHA) class III or IV and who have an ejection fraction of $50 \%$ or less (Table 4) (13).

3. TB screening for biologic agents (level of evidence C for all recommendations except for initiation of biologic agents in patients being treated for latent TB infection [LTBI], where the level of evidence is B). The panel recommends screening to identify LTBI in all RA patients being considered for therapy with biologic agents, regardless of the presence of risk factors for LTBI (diamond A of Figure 3) (14). It recommends that clinicians assess the patient's medical history to identify risk factors for TB (specified by the CDC) (Table 2).

The panel recommends the tuberculin skin test (TST) or interferon- $\gamma$-release assays (IGRAs) as the initial test in all RA patients starting biologic agents, regardless of risk factors for LTBI (diamond A of Figure 3). It recommends the use of the IGRA over the TST in patients who had previ- 


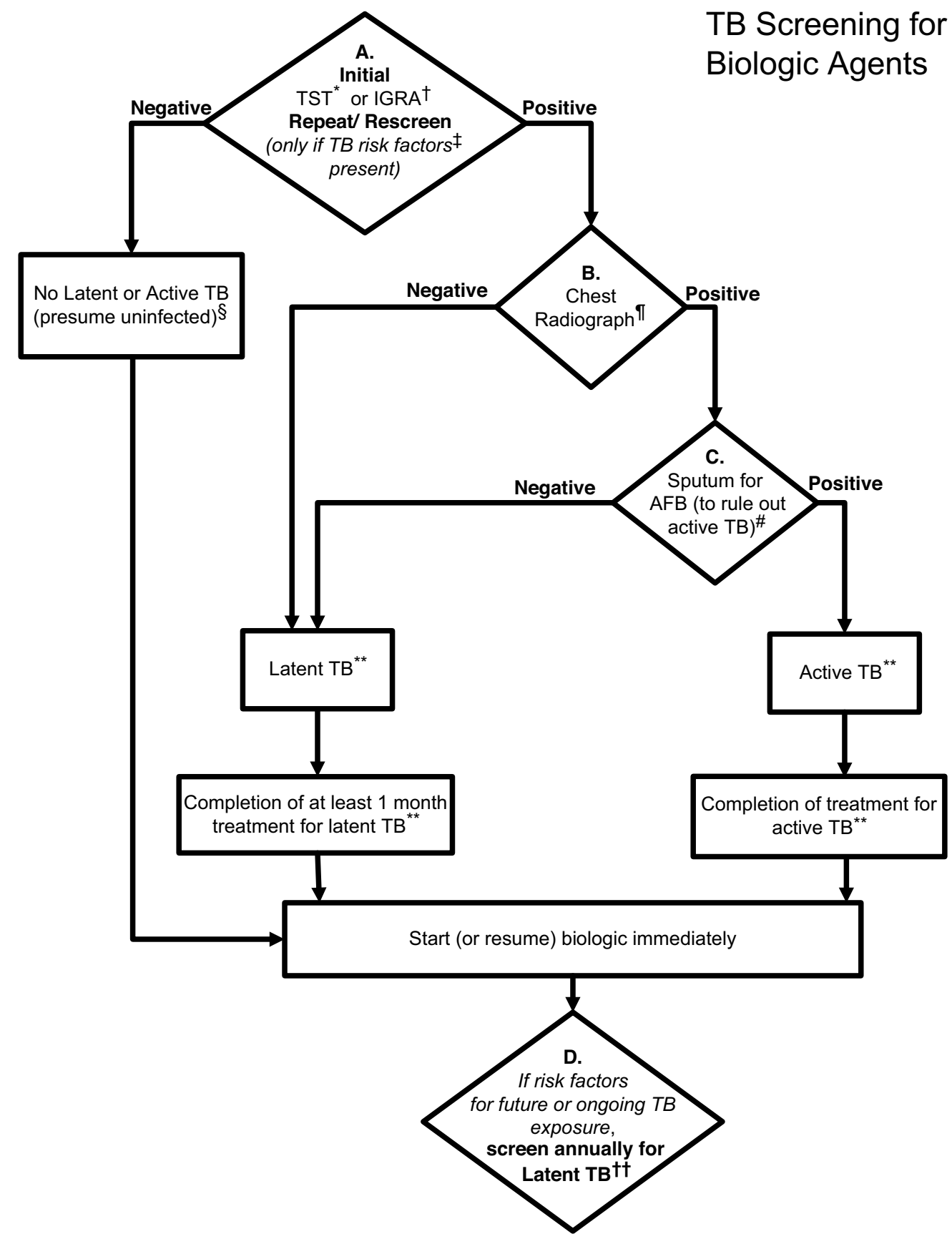

Figure 3. 2012 American College of Rheumatology recommendations update for tuberculosis (TB) screening with biologic agent use. Depending on a patient's current therapy, the management may begin at an appropriate rectangle in the figure, rather than only at the top of the figure. The level of evidence supporting each recommendation for TB reactivation was "C," except for initiation of biologic agents in patients being treated for latent TB infection, where the level of evidence was "B."

* Anergy panel testing is not recommended.

t Interferon- $\gamma$-release assay (IGRA) is preferred if the patient has a history of BCG vaccination.

¥ Risk factors for TB exposure are defined based on a publication from the US Centers for Disease Control and Prevention as: close contacts of persons known or suspected to have active TB; foreign-born persons from areas that have a high incidence of active TB (e.g., Africa, Asia, Eastern Europe, Latin America, and Russia); persons who visit areas with a high prevalence of active TB, especially if visits are frequent or prolonged; residents and employees of congregate settings whose clients are at an increased risk for active TB (e.g., correctional facilities, long-term care facilities, and homeless shelters); health care workers who serve clients who are at an increased risk for active TB; populations defined locally as having an increased incidence of latent Mycobacterium tuberculosis infection or active TB, possibly including medically underserved, low-income populations, or persons who abuse drugs or alcohol; and infants, children, and adolescents exposed to adults who are at an increased risk for latent $M$ tuberculosis infection or active TB (14).

$\S$ If the patient is immunosuppressed and false-negative results are more likely, consider repeating screening test(s) with tuberculin skin test (TST) or IGRA.

II Chest radiograph may also be considered when clinically indicated in patients with risk factors, even with a negative repeat TST or IGRA.

\# Obtain respiratory (e.g., sputum, bronchoalveolar lavage fluid) or other samples as clinically appropriate for acid-fast bacilli (AFB) smear and culture and consider referral to a TB specialist for further evaluation and treatment.

** In a patient diagnosed with latent or active TB, consider referral to a specialist for the recommended treatment.

t+ Patients who test positive for TST or IGRA at baseline often remain positive for these tests even after successful treatment of TB. These patients need monitoring for clinical signs and symptoms of recurrent TB disease, since repeating tests will not allow help in diagnosis of recurrent TB. 
Table 5. 2012 American College of Rheumatology recommendations update regarding the use of vaccines in patients with $\mathrm{RA}$ starting or currently receiving DMARDs or biologic agents*

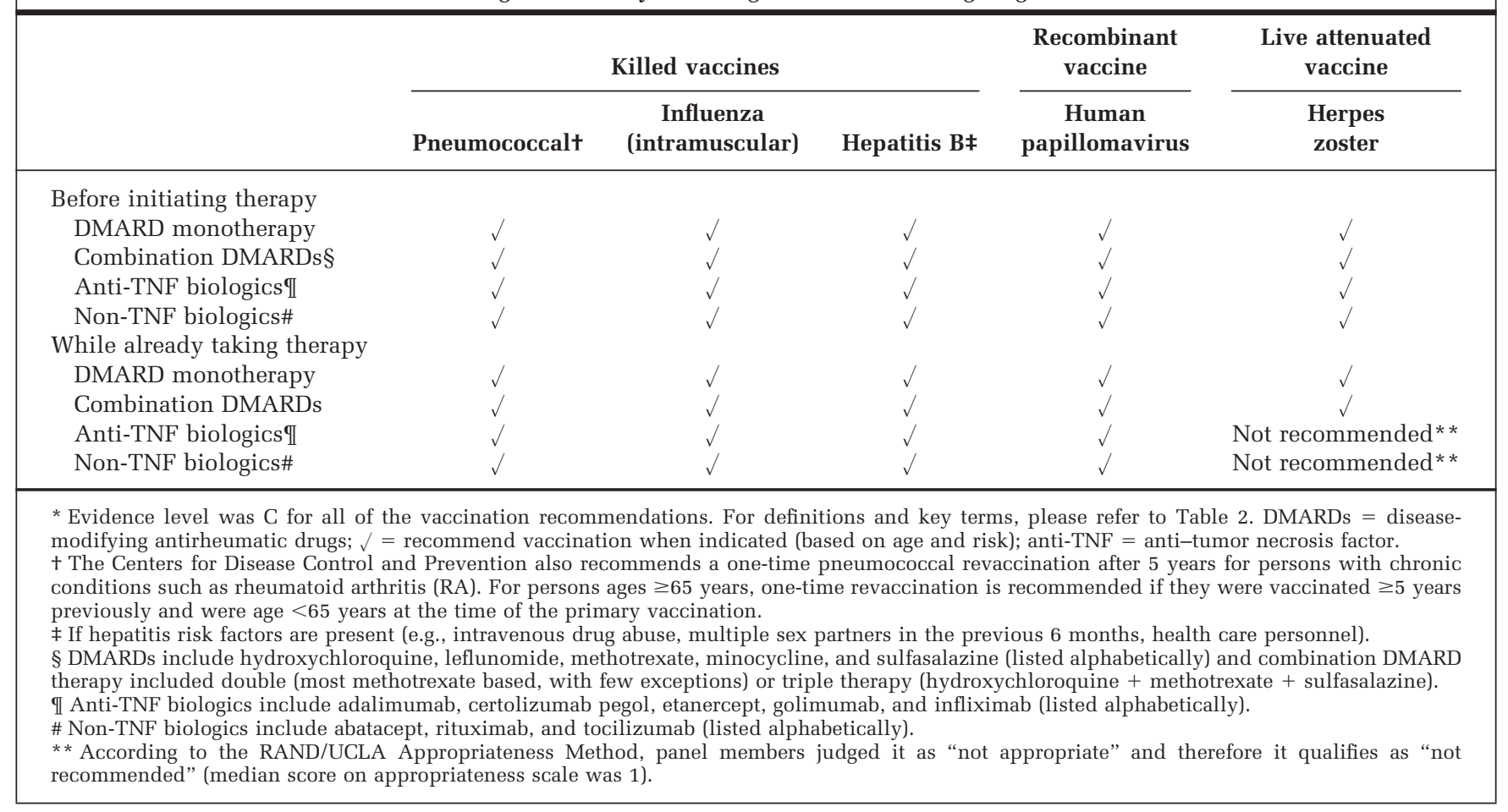

ously received a BCG vaccination, due to the high falsepositive test rates for TST (Figure 3).

The panel recommends that RA patients with a positive initial or repeat TST or IGRA should have a chest radiograph and, if suggestive of active TB, a subsequent sputum examination to check for the presence of active TB (diamonds B and C of Figure 3). RA patients with a negative screening TST or IGRA may not need further evaluation in the absence of risk factors and/or clinical suspicion for TB. Since patients with RA may have false-negative TST or IGRA results due to immunosuppression, a negative TST or IGRA should not be interpreted as excluding the possibility that a patient has LTBI. Accordingly, in immunosuppressed RA patients with risk factors for LTBI and negative initial screening tests, the panel recommends that a repeat TST or IGRA could be considered 1-3 weeks after the initial negative screening (diamond A of Figure 3).

If the RA patient has active or latent TB based on the test results, the panel recommends appropriate antitubercular treatment and consideration of referral to a specialist. Treatment with biologic agents can be initiated or resumed after 1 month of latent TB treatment with antitubercular medications and after completion of the treatment of active TB, as applicable (Figure 3).

The panel recommends annual testing in RA patients who live, travel, or work in situations where TB exposure is likely while they continue treatment with biologic agents (diamond D of Figure 3). Patients who test positive for TST or IGRA at baseline can remain positive for these tests even after successful treatment of TB. These patients need monitoring for clinical signs and symptoms of recurrent $\mathrm{TB}$, since repeating tests will not help in the diagnosis of recurrent TB.
4. Vaccination in patients starting or currently receiving DMARDs or biologic agents as part of their RA therapy (level of evidence $\boldsymbol{C}$ for all recommendations). The panel recommends that all killed (pneumococcal, influenza intramuscular, and hepatitis B), recombinant (human papillomavirus [HPV] vaccine for cervical cancer), and live attenuated (herpes zoster) vaccinations should be undertaken before starting a DMARD or a biologic agent (Table 5).

It also recommends that, if not previously done, vaccination with indicated pneumococcal (killed), influenza intramuscular (killed), hepatitis B (killed), and HPV vaccine (recombinant) should be undertaken in RA patients already taking a DMARD or a biologic agent (Table 5).

The panel recommends vaccination with herpes zoster vaccine in RA patients already taking a DMARD. All vaccines should be given based on age and risk, and physicians should refer to vaccine instructions and CDC recommendations for details about dosing and timing issues related to vaccinations.

\section{Discussion}

We updated the 2008 ACR RA recommendations for the treatment of RA (1) using the scientific evidence and a rigorous evidence-based group consensus process. The 2012 update addresses the use of DMARDs and biologic agents, switching between therapies, the use of biologic agents in high-risk patients, TB screening with the use of biologic agents, and vaccination in patients with RA receiving DMARDs or biologic agents.

The rigorous process to which we referred above included a comprehensive updated literature review, data 
review by a panel of international experts, and use of a well-accepted validated process for developing recommendations (2-4).

Because we used the same method for this update as the 2008 ACR RA recommendations, we were able to incorporate the evidence from the 2008 process and comprehensively update the recommendations. Consistent with the common need to extrapolate from clinical experience in the absence of higher-tier evidence, many of these new recommendations (approximately 79\%) were associated with level $\mathrm{C}$ evidence.

These recommendations aim to address common questions facing both patients with RA and the treating health care providers. Since the recommendations were derived considering the "common patients, not exceptional cases," they are likely to be applicable to a majority of RA patients, although not all patients. As always, clinical judgment must be used. The emergence of several new therapies for RA in the last decade has led to great excitement in the field of rheumatology as well as provided patients and health care providers with multiple options for treatment.

The 2008 recommendations and 2012 update attempt to simplify the treatment algorithms for patients and providers. These recommendations provide clinicians with choices for treatments of patients with active RA, both in early and established disease phases.

Recommendations also provide guidance regarding treatment choices in RA patients with comorbidities such as hepatitis, CHF, and malignancy. In particular, the risk for TB reactivation has become an increasingly common concern for clinicians and patients treating RA patients with biologic agents. The algorithm recommended provides a comprehensive approach for many RA patients. Due to an increasing awareness of risk of preventable diseases such an influenza and pneumonia (especially in the elderly), immunizations are very important in patients with RA. Several recommendations address this important aspect of vaccination of RA patients. Because these recommendations were heavily informed by CDC guidance and minimal additional information was found in the broader literature search, our TB screening and vaccination recommendations are concordant with the CDC recommendations.

The goal for each RA patient should be low disease activity or remission. In ideal circumstances, RA remission should be the target of therapy, but in others, low disease activity may be an acceptable target. But for other patients, the decision about what the target should be for each patient is appropriately left to the clinician caring for each RA patient, in the context of patient preferences, comorbidities, and other individual considerations. Therefore, this article does not recommend a specific target for all patients. Of note, the panel recommended more aggressive treatment in patients with early RA than in the 2008 ACR recommendations. We speculate that this may be related to several reasons: 1) the expectation that the earlier the treatment the better the outcome, 2) the thought that joint damage is largely irreversible so prevention of damage is an important goal, and 3) the data that early intensive therapy may provide the best opportunity to preserve physical function and health-related quality of life and reduce work-related disability (15-22).
As with all recommendations, these recommendations apply to common clinical scenarios, and only a clinician's assessment in collaboration with the patient allows for the best risk-benefit analysis on a case-by-case basis. These recommendations cannot adequately convey all uncertainties and nuances of patient care in the real world. For example, the panel did not vote on the possibility of temporarily holding biologic therapy to facilitate administration of the live herpes zoster vaccine among older patients and then resuming the biologic agent shortly thereafter. All recommendations were based on scientific evidence coupled with our formal group process rather than only the approved indications from regulatory agencies. Although new classification criteria for RA (ACR/European League Against Rheumatism collaborative initiative) were published in September 2010 (23), the studies evaluated for the 2012 recommendations relied on the use of the 1987 ACR RA classification criteria (24) because our literature review preceded the publication of the new criteria.

The need to create recommendations that cover a comprehensive array of relevant clinical decisions has led to many recommendations that combine literature-based data and expert opinion, and thus are labeled as level C evidence. For example, rituximab was recommended as appropriate in patients with previously treated solid malignancy within the last 5 years or a previously treated nonmelanoma skin cancer within the last 5 years, which is a level $\mathrm{C}$ recommendation since the evidence is based on clinical trial extensions and observational data. It is important to note that the limited evidence available supporting this recommendation comes primarily from non-RA populations that included cancer patients. In addition, the panel ratings did not achieve the level of appropriateness needed to recommend other biologic therapies in this circumstance since most of the panelists' ratings were "uncertain." Like many of the other recommendations put forth, this recommendation was grounded, in part, on expert consensus and serves to highlight an important evidence gap in RA management.

In some cases the panelists did not make a specific recommendation statement. This occurred when ratings reflected uncertainty over a particular potential clinical scenario or when there was inability to reach consensus. In these cases, given a lack of clear evidence or clear consensus, therapeutic decisions are best left to the careful consideration of risks/benefits by the individual patient and physician. These areas could be the subject of future research agendas and recommendations updates.

We anticipate that in the future, data using the new RA classification criteria (23) may be available for evidence synthesis and formulating recommendations. Recommendations regarding the use of other antiinflammatory medications, such as nonsteroidal antiinflammatory drugs and intraarticular and oral corticosteroids, and nonpharmacologic therapies (such as physical and occupational therapies) were not within the purview of this update, although these may be important components of RA treatment and could also be included in separate reviews or recommendations. For example, recommendations related to glucocorticoid use in RA have been published by other professional organizations (25). In the future, the ACR may decide to develop broader RA guidelines that include ther- 
apies that are not in this article. In addition, due to the infrequent use of gold, anakinra, cyclosporine, and azathioprine, scenarios for these medications were not included in this update.

In summary, we provide updated recommendations for the use of nonbiologic and biologic treatments in RA following the same methodology used to develop the 2008 ACR RA recommendations. While these recommendations are extensive and include new areas and new agents not covered in 2008, they are not comprehensive. These recommendations, which focus on common clinical scenarios, should be used as a guide for clinicians treating RA patients, with the clear understanding that the best treatment decision can only be made by the clinician in discussions with patients, taking into account their risk/benefit assessment, including consideration of comorbidities and concomitant medications, patient preferences, and practical economic considerations. These recommendations are not intended to determine criteria for payment or coverage of health care services. As with this 2012 update, the ACR plans to periodically update RA treatment recommendations depending upon the availability of new therapies, new evidence on the benefits and harms of existing treatments, and changes in policies to reflect the rapidly evolving cutting-edge care of RA patients.

Addendum. Therapies that were approved after the original literature review are not included in these recommendations.

\section{ACKNOWLEDGMENTS}

We thank Ms Mary Elkins Melton for administrative support, the ACR staff (Ms Regina Parker and Ms Amy Miller) for assistance in organizing the face-to-face meeting, and Ms Amy Miller for help in revision of the manuscript. We thank Dr. Michael Saag (University of Alabama at Birmingham) for providing expert advice regarding new literature related to clinical scenarios of infection risk in the context of biologic agents. We thank our 2 clinical colleagues, Dr. Anthony Turkiewicz and Dr. Gary Feldman, for reviewing the recommendations and providing initial comments. We thank Dr. Cheryl Perry of the University of Alabama at Birmingham Center for Clinical and Translational Science for her help in copyediting this manuscript. We thank Dr. Ruiz Garcia of Médico Adjunto de la Unidad de Hospitalización a Domicilio, Spain, for providing data from their Cochrane systematic review on certolizumab pegol in RA.

\section{AUTHOR CONTRIBUTIONS}

All authors were involved in drafting the article or revising it critically for important intellectual content, and all authors approved the final version to be published. Dr. Singh had full access to all of the data in the study and takes responsibility for the integrity of the data and the accuracy of the data analysis.

Study conception and design. Singh, Furst, Bharat, Curtis, Moreland, O'Dell, Beukelman, Bridges, Paulus, Suarez-Almazor, Dougados, Jain, Agrawal, Patkar, Saag.

Acquisition of data. Singh, Furst, Bharat, Kavanaugh, Kremer, Beukelman, Bombardier, Dougados, Khanna, King, Jain, Volkmann, Agrawal, Bae, Patkar, Saag.

Analysis and interpretation of data. Singh, Furst, Bharat, Curtis, Kavanaugh, Kremer, Moreland, O’Dell, Winthrop, Beukelman,
Bridges, Chatham, Paulus, Suarez-Almazor, Dougados, Khanna, King, Leong, Matteson, Schousboe, Moynihan, Kolba, Agrawal, Mudano, Patkar, Saag.

\section{REFERENCES}

1. Saag KG, Teng GG, Patkar NM, Anuntiyo J, Finney C, Curtis JR, et al. American College of Rheumatology 2008 recommendations for the use of nonbiologic and biologic disease-modifying antirheumatic drugs in rheumatoid arthritis. Arthritis Rheum 2008;59:762-84.

2. McGory ML, Shekelle PG, Rubenstein LZ, Fink A, Ko CY. Developing quality indicators for elderly patients undergoing abdominal operations. J Am Coll Surg 2005;201:870-83.

3. Shekelle P. The appropriateness method. Med Decis Making 2004;24:228-31.

4. Shekelle PG, Park RE, Kahan JP, Leape LL, Kamberg CJ, Bernstein SJ. Sensitivity and specificity of the RAND/UCLA Appropriateness Method to identify the overuse and underuse of coronary revascularization and hysterectomy. J Clin Epidemiol 2001;54:1004-10.

5. Singh JA, Noorbaloochi S, Singh G. Golimumab for rheumatoid arthritis. Cochrane Database Syst Rev 2010;1:CD008341.

6. Singh JA, Beg S, Lopez-Olivo MA. Tocilizumab for rheumatoid arthritis. Cochrane Database Syst Rev 2010;7:CD008331.

7. Singh JA, Christensen R, Wells GA, Suarez-Almazor ME, Buchbinder R, Lopez-Olivo MA, et al. Biologics for rheumatoid arthritis: an overview of Cochrane reviews. Cochrane Database Syst Rev 2009;4:CD007848.

8. Ruiz Garcia V, Jobanputra P, Burls A, Cabello JB, Galvez Munoz JG, Saiz Cuenca ES, et al. Certolizumab pegol (CDP870) for rheumatoid arthritis in adults. Cochrane Database Syst Rev 2009;2:CD007649.

9. Landis JR, Koch GG. The measurement of observer agreement for categorical data. Biometrics 1977;33:159-74.

10. FDA, US Department of Health and Human Services. What is a serious adverse event? 2011. URL: http://www.fda.gov/ safety/medwatch/howtoreport/ucm053087.htm.

11. Hunt SA, Abraham WT, Chin MH, Feldman AM, Francis GS, Ganiats TG, et al. ACC/AHA 2005 guideline update for the diagnosis and management of chronic heart failure in the adult: a report of the American College of Cardiology/American Heart Association Task Force on Practice Guidelines (Writing Committee to Update the 2001 Guidelines for the Evaluation and Management of Heart Failure). Developed in collaboration with the American College of Chest Physicians and the International Society for Heart and Lung Transplantation: endorsed by the Heart Rhythm Society. Circulation 2005;112:e154-235.

12. Christensen E, Schlichting P, Fauerholdt L, Gluud C, Andersen PK, Juhl E, et al. Prognostic value of Child-Turcotte criteria in medically treated cirrhosis. Hepatology 1984;4:430-5.

13. Hurst JW, Morris DC, Alexander RW. The use of the New York Heart Association's classification of cardiovascular disease as part of the patient's complete Problem List. Clin Cardiol 1999; 22:385-90.

14. CDC. Targeted tuberculin testing and treatment of latent tuberculosis infection. MMWR Mortal Morb Wkly Rep 2000;49: $1-51$.

15. Bejarano V, Quinn M, Conaghan PG, Reece R, Keenan AM, Walker D, et al, and the Yorkshire Early Arthritis Register Consortium. Effect of the early use of the anti-tumor necrosis factor adalimumab on the prevention of job loss in patients with early rheumatoid arthritis. Arthritis Rheum 2008;59: 1467-74.

16. Emery P, Breedveld FC, Hall S, Durez P, Chang DJ, Robertson $\mathrm{D}$, et al. Comparison of methotrexate monotherapy with a combination of methotrexate and etanercept in active, early, moderate to severe rheumatoid arthritis (COMET): a randomised, double-blind, parallel treatment trial. Lancet 2008; 372:375-82.

17. Han C, Smolen J, Kavanaugh A, St.Clair EW, Baker D, Bala M. Comparison of employability outcomes among patients with early or long-standing rheumatoid arthritis. Arthritis Rheum 2008;59:510-4. 
18. Kimel M, Cifaldi M, Chen N, Revicki D. Adalimumab plus methotrexate improved SF-36 scores and reduced the effect of rheumatoid arthritis (RA) on work activity for patients with early RA. J Rheumatol 2008;35:206-15.

19. Smolen JS, Han C, van der Heijde D, Emery P, Bathon JM, Keystone E, et al. Infliximab treatment maintains employability in patients with early rheumatoid arthritis. Arthritis Rheum 2006;54:716-22.

20. St.Clair EW, van der Heijde DM, Smolen JS, Maini RN, Bathon JM, Emery P, et al, for the Active-Controlled Study of Patients Receiving Infliximab for the Treatment of Rheumatoid Arthritis of Early Onset Study Group. Combination of infliximab and methotrexate therapy for early rheumatoid arthritis: a randomized, controlled trial. Arthritis Rheum 2004;50:343243.

21. Van der Kooij SM, le Cessie S, Goekoop-Ruiterman YP, de Vries-Bouwstra JK, van Zeben D, Kerstens PJ, et al. Clinical and radiological efficacy of initial vs delayed treatment with infliximab plus methotrexate in patients with early rheumatoid arthritis. Ann Rheum Dis 2009;68:1153-8.

22. Bathon JM, Martin RW, Fleischmann RM, Tesser JR, Schiff $\mathrm{MH}$, Keystone EC, et al. A comparison of etanercept and methotrexate in patients with early rheumatoid arthritis. N Engl J Med 2000;22:1586-93.

23. Aletaha D, Neogi T, Silman AJ, Funovits J, Felson DT, Bingham CO III, et al. 2010 rheumatoid arthritis classification criteria: an American College of Rheumatology/European League Against Rheumatism collaborative initiative. Arthritis Rheum 2010;62:2569-81.

24. Arnett FC, Edworthy SM, Bloch DA, McShane DJ, Fries JF, Cooper NS, et al. The American Rheumatism Association 1987 revised criteria for the classification of rheumatoid arthritis. Arthritis Rheum 1988;31:315-24.

25. Smolen JS, Landewe R, Breedveld FC, Dougados M, Emery P, Gaujoux-Viala C, et al. EULAR recommendations for the management of rheumatoid arthritis with synthetic and biological disease-modifying antirheumatic drugs. Ann Rheum Dis 2010;69:964-75.

26. Aletaha D, Smolen JS. The definition and measurement of disease modification in inflammatory rheumatic diseases. Rheum Dis Clin North Am 2006;32:9-44.

27. Aletaha D, Ward MM, Machold KP, Nell VP, Stamm T, Smolen JS. Remission and active disease in rheumatoid arthritis: defining criteria for disease activity states. Arthritis Rheum 2005;52:2625-36.

28. Felson DT, Anderson JJ, Boers M, Bombardier C, Furst D, Goldsmith C, et al. American College of Rheumatology preliminary definition of improvement in rheumatoid arthritis. Arthritis Rheum 1995;38:727-35.

29. Pincus T. The American College of Rheumatology (ACR) core data set and derivative "patient only" indices to assess rheumatoid arthritis. Clin Exp Rheumatol 2005;23 Suppl:S10913.

30. Wells GA, Boers M, Shea B, Brooks PM, Simon LS, Strand CV, et al. Minimal disease activity for rheumatoid arthritis: a preliminary definition. J Rheumatol 2005;32:2016-24.

31. Wolfe F, Michaud K, Pincus T. A composite disease activity scale for clinical practice, observational studies, and clinical trials: the Patient Activity Scale (PAS/PAS-II). J Rheumatol 2005;32:2410-5.

32. Wolfe F, Michaud K, Pincus T, Furst D, Keystone E. The
Disease Activity Score is not suitable as the sole criterion for initiation and evaluation of anti-tumor necrosis factor therapy in the clinic: discordance between assessment measures and limitations in questionnaire use for regulatory purposes. Arthritis Rheum 2005;52:3873-9.

33. Agrawal S, Misra R, Aggarwal A. Autoantibodies in rheumatoid arthritis: association with severity of disease in established RA. Clin Rheumatol 2007;26:201-4.

34. Ates A, Kinikli G, Turgay M, Akay G, Tokgoz G. Effects of rheumatoid factor isotypes on disease activity and severity in patients with rheumatoid arthritis: a comparative study. Clin Rheumatol 2007;26:538-45.

35. Berglin E, Johansson T, Sundin U, Jidell E, Wadell G, Hallmans G, et al. Radiological outcome in rheumatoid arthritis is predicted by presence of antibodies against cyclic citrullinated peptide before and at disease onset, and by IgA-RF at disease onset. Ann Rheum Dis 2006;65:453-8.

36. Meyer O, Labarre C, Dougados M, Goupille P, Cantagrel A, Dubois A, et al. Anticitrullinated protein/peptide antibody assays in early rheumatoid arthritis for predicting five year radiographic damage. Ann Rheum Dis 2003;62:120-6.

37. Vencovsky J, Machacek S, Sedova L, Kafkova J, Gatterova J, Pesakova V, et al. Autoantibodies can be prognostic markers of an erosive disease in early rheumatoid arthritis. Ann Rheum Dis 2003;62:427-30.

38. Brook A, Corbett M. Radiographic changes in early rheumatoid disease. Ann Rheum Dis 1977;36:71-3.

39. Wells G, Becker JC, Teng J, Dougados M, Schiff M, Smolen J, et al. Validation of the 28-joint Disease Activity Score (DAS28) and European League Against Rheumatism response criteria based on C-reactive protein against disease progression in patients with rheumatoid arthritis, and comparison with the DAS28 based on erythrocyte sedimentation rate. Ann Rheum Dis 2009;68:954-60.

40. Bresnihan B. Preventing joint damage as the best measure of biologic drug therapy. J Rheumatol Suppl 2002;65:39-43.

41. Felson DT, Smolen JS, Wells G, Zhang B, van Tuyl LH, Funovits J, et al. American College of Rheumatology/European League Against Rheumatism provisional definition of remission in rheumatoid arthritis for clinical trials. Arthritis Rheum 2011;63:573-86.

42. Pincus T, Yazici Y, Bergman M. A practical guide to scoring a Multi-Dimensional Health Assessment Questionnaire (MDHAQ) and Routine Assessment of Patient Index Data (RAPID) scores in 10-20 seconds for use in standard clinical care, without rulers, calculators, websites or computers. Best Pract Res Clin Rheumatol 2007;21:755-87.

43. Aletaha D, Nell VP, Stamm T, Uffmann M, Pflugbeil S, Machold K, et al. Acute phase reactants add little to composite disease activity indices for rheumatoid arthritis: validation of a clinical activity score. Arthritis Res Ther 2005;7:R796806.

44. Fransen J, Stucki G, van Riel PL. Disease Activity Score (DAS), Disease Activity Score-28 (DAS28), Rapid Assessment of Disease Activity in Rheumatology (RADAR), and Rheumatoid Arthritis Disease Activity Index (RADAI). Arthritis Rheum 2003;49 Suppl:S214-24.

45. Smolen JS, Breedveld FC, Schiff MH, Kalden JR, Emery P, Eberl G, et al. A simplified disease activity index for rheumatoid arthritis for use in clinical practice. Rheumatology (Oxford) $2003 ; 42: 244-57$. 